\title{
Uric acid participating in female reproductive disorders: a review
}

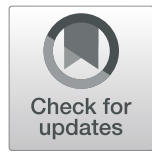

Junhao $\mathrm{Hu}^{1 \dagger}$, Wenyi $\mathrm{Xu}^{1+}$, Haiyan Yang ${ }^{1^{*}}$ and Liangshan $\mathrm{Mu}^{2^{*}}$

\begin{abstract}
Uric acid (UA) is the end metabolic product of purine metabolism. Early on, UA was considered to be a metabolite with a certain antioxidant capacity. As research has progressed, other properties of UA have been explored, and its association with many diseases has been found. The association between UA and kidney disease and cardiovascular disease is well established; however, there is still a paucity of reviews on the association between UA and the female reproductive system. An increasing number of epidemiological studies have shown elevated serum UA levels in patients with polycystic ovary syndrome (PCOS), endometriosis, etc. Additionally, serum UA can be used as a predictor of pregnancy complications and adverse foetal outcomes. An increasing number of animal experiments and clinical studies have revealed possible mechanisms related to the involvement of UA in certain female reproductive disorders: oxidative stress, chronic inflammation, mitochondrial dysfunction, etc. This article reviews the current mainstream mechanisms regarding the pathogenesis of UA and the role of UA in certain specific female reproductive disorders (direct involvement in the development of certain diseases or enhancement of other risk factors) in the hope of contributing to clinical prevention, diagnosis, treatment and improvement in prognosis.
\end{abstract}

Keywords: Uric acid, Polycystic ovary syndrome, Endometriosis, Pregnancy complications

\section{Background}

Previous studies have revealed that physiological levels of uric acid (UA) have a protective function in vivo due to their antioxidant effect [1]. However, excessive serum UA levels are also a risk factor for kidney disease, cardiovascular disease, and metabolic syndrome $[2,3]$. Some literature has reported that UA levels tend to be elevated to higher levels in some patients, such as those with polycystic ovary syndrome (PCOS), and correlate with clinical severity [4]. Additionally, trials targeting drugs to control UA levels have provided positive results, and some scholars have used UA levels to predict the occurrence of pregnancy complications and adverse

\footnotetext{
*Correspondence: 13957720491@163.com; liangshanmu@zju.edu.cn

${ }^{\dagger} J u n h a o \mathrm{Hu}$ and Wenyi Xu contributed equally to this article.

${ }^{1}$ Reproductive Medicine Center, The First Affiliated Hospital of Wenzhou Medical University, No.96 Fuxue Road, 325000 Wenzhou, People's Republic of China

${ }^{2}$ School of Medicine, Zhejiang University, No.866 Yuhantang Road, 310058 Hangzhou, People's Republic of China
}

maternal and infant risks [5-8]. These findings led us to question whether there is a close relationship between UA and female reproductive disorders. Based on these reports, we suggest that these reproductive disorders may be influenced by multiple factors, such as increased oxidative stress due to UA accumulation, inflammation, and mitochondrial dysfunction. In this paper, we review the evidence for the multiple adverse effects of UA levels on the female reproductive system and highlight the potential pathophysiological significance of UA in women.

\section{Uric Acid}

UA is a major product of purine metabolism catalysed by xanthine oxidoreductase (XOR). Plasma UA levels can be increased by exogenous pathways such as excessive intake of high-purine and high-fructose foods and are mainly affected by catabolism from endogenous pathways such as those in the liver and small intestine [9]. Hyperuricaemia is an elevated UA level in the blood,

(c) The Author(s). 2021 Open Access This article is licensed under a Creative Commons Attribution 4.0 International License, which permits use, sharing, adaptation, distribution and reproduction in any medium or format, as long as you give appropriate credit to the original author(s) and the source, provide a link to the Creative Commons licence, and indicate if changes were made. The images or other third party material in this article are included in the article's Creative Commons licence, unless indicated otherwise in a credit line to the material. If material is not included in the article's Creative Commons licence and your intended use is not permitted by statutory regulation or exceeds the permitted use, you will need to obtain permission directly from the copyright holder. To view a copy of this licence, visit http://creativecommons.org/licenses/by/4.0/ The Creative Commons Public Domain Dedication waiver (http://creativecommons.org/publicdomain/zero/1.0/) applies to the data made available in this article, unless otherwise stated in a credit line to the data. 
defined as wither $>7.0 \mathrm{mg} / \mathrm{dL}$ or $>6.0 \mathrm{mg} / \mathrm{dL}$ of serum UA for most studies. A variety of enzymes are involved in the synthesis of UA. The nucleotides in the cell are acted upon by nucleotidase to produce nucleosides, which are acted upon by nucleoside phosphorylase to produce bases. Among these purine bases, xanthine is produced by xanthine oxidase $(\mathrm{XO})$, and $\mathrm{UA}$ is further produced by the action of this enzyme (Fig. 1). XOR is the key enzyme in this process and has two convertible forms: xanthine dehydrogenase $(\mathrm{XDH})$ and $\mathrm{XO} . \mathrm{XDH}$ can convert NAD ${ }^{+}$to $\mathrm{NADH}$ via $\mathrm{FADH}_{2}$, while XO can convert $\mathrm{O}_{2}$ to hydrogen peroxide and free radical superoxide anion $\left(\mathrm{O}_{2}{ }^{-}{ }^{-}\right)$via FAD [10]. Thus, XOR can be one of the sources of reactive oxygen species (ROS) production. Moreover, XOR is active in the liver, intestine, and endothelium, so it can also cause oxidative stress and endothelial dysfunction. Approximately $2 / 3$ of UA is excreted by the kidneys, and the rest is excreted by the gastrointestinal tract [11]. The main transporter associated with the reabsorption of UA in renal tubules is urate transporter 1 (URAT1), the main UA-secreting transporters are organic anion transporter 4 (OAT4) and glucose transporter 9 (GLUT9), and the amount of transporter can affect the level of serum UA to a certain extent [12].

UA is also found in the follicular fluid of the female ovary. Studies on buffalo ovaries have proven that disruption of the plasma-follicular barrier structure is associated with increased levels of UA [13]. In addition, hypoxanthine can inhibit oocyte meiosis, suggesting a possible decrease in fertility [14].

\section{Uric Acid in oxidative stress and mitochondrial dysfunction}

UA is a known antioxidant and is a major contributor to antioxidant potential in vivo. UA not only removes singlet oxygen and free radicals but also reduces the damage of peroxynitrite to proteins involved in nearly half of the antioxidant effects in vivo [1]. UA has shown antioxidant effects in humans under many conditions and can rapidly return to its antioxidant status through the action of ascorbic acid [15]. At physiological concentrations, UA reduces the formation of oxyhaeme oxidants via peroxides that react with haemoglobin while preventing erythrocyte lipid peroxidation and protecting erythrocyte lysis due to peroxidation damage [10]. However, when the availability of antioxidants such as ascorbic acid decreases, UA will become an oxidant and participate in the occurrence of various pathological processes dominated by oxidative stress in the body.

Oxidative stress is related to the pathogenesis of many diseases, including cardiovascular disease, cancer, and neurodegenerative diseases $[16,17]$. The presence of an oxidative stress state has also been reported in many female reproductive disorders, such as PCOS and preeclampsia (PE) $[18,19]$. Oxidative stress occurs mainly from an imbalance between ROS production and the antioxidant defence system, and UA also seems to be involved in this process. As previously mentioned, UA is produced by $\mathrm{XO}$ and $\mathrm{XDH}$, which together catalyse the oxidation of purines. Under normal conditions, $\mathrm{XDH}$ is the main substance involved in this reaction; however,

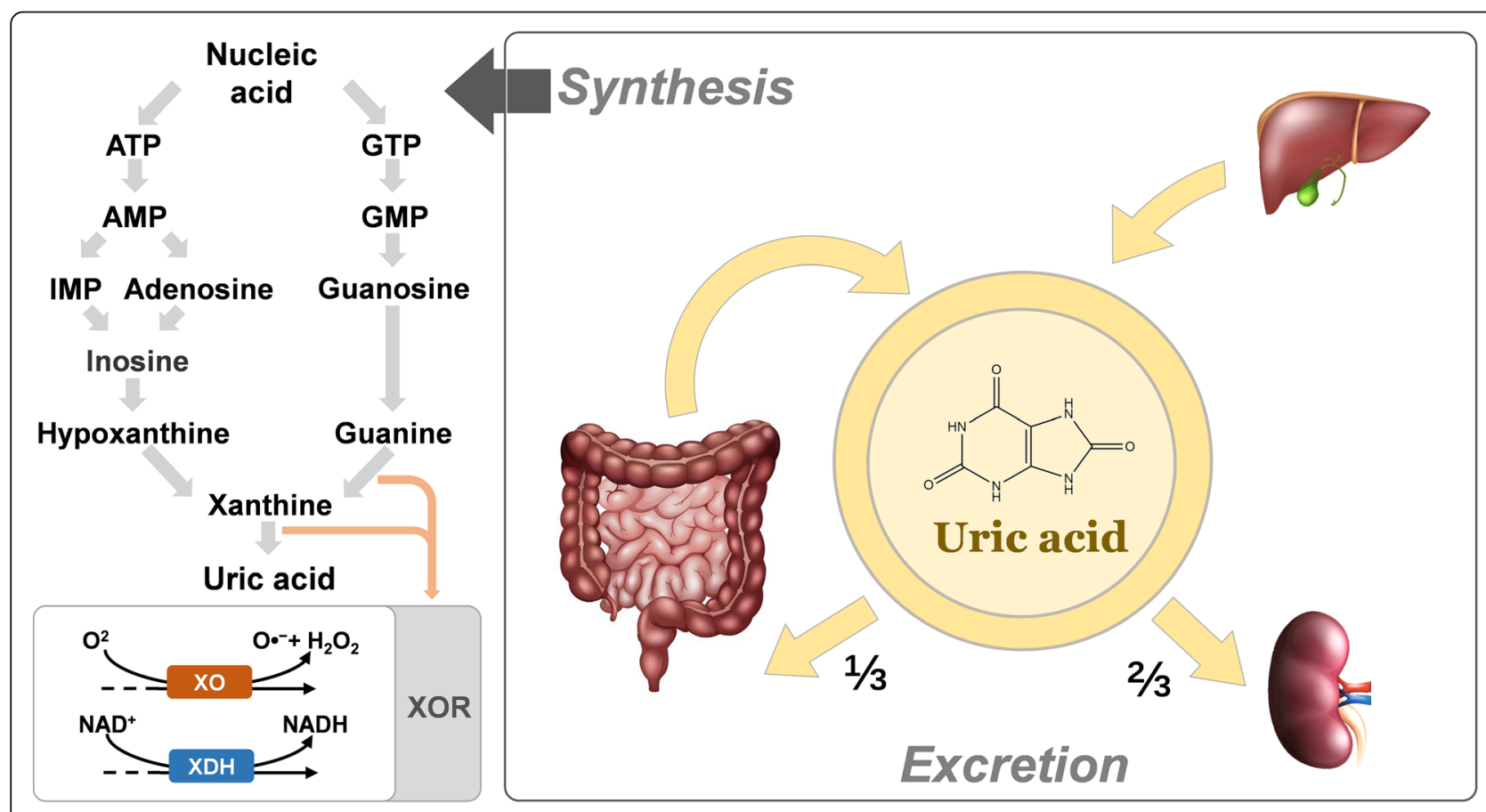

Fig. 1 The metabolic process of uric acid 
the activity of $\mathrm{XO}$ is enhanced under specific conditions, such as oxidative stress. $\mathrm{XO}$ is an important source of superoxide radicals. It can utilize molecular oxygen to produce UA along with active superoxide radicals and hydrogen peroxide [11]. Generated ROS can not only alter the normal function of mitochondria but also in turn produce excess ROS that may diffuse into the cytoplasm [20]. When the production of these superoxide free radicals increases excessively or is absolutely or relatively insufficient, the circulating ROS will increase significantly, leading to the development of oxidative stress in the body.

In addition to inducing oxidative stress, high concentrations of serum UA also affect lipid synthesis and lipid oxidation distortion. High levels of UA stimulate the $\mathrm{NADPH}$ oxidase isoform NADPH oxidase 4 (NOX4) in mitochondria, which increases superoxide production and consequently decreases aconitase activity. This leads to the accumulation of its substrate citric acid, promoting its re-catabolism to acetyl-CoA for lipid synthesis [21]. Excessive fat deposition promotes the production of pro-inflammatory factors such as IL- $1 \beta$, which can further mediate lipid oxidative stress through the NF- $\mathrm{kB}$ and NADPH oxidase pathways [22]. In addition, disorders of lipid metabolism are associated with an imbalanced state of AMP-activated kinase (AMPK) and AMP deaminase (AMPD), a pair of enzymes with mutually antagonistic effects. Intracellular UA accumulation reverses physiological homeostasis and promotes fat accumulation and gluconeogenesis by activating AMPD and inhibiting AMPK [23]. Whereas adipose tissue is rich in XOR, obesity increases XOR mRNA expression, which in turn promotes UA secretion [21].

Abnormal lipid metabolism, on the one hand, produces lipotoxicity, which has a direct adverse effect on cells, and on the other hand can produce large amounts of ROS, which induces stress damage to intracellular organelles leading to cell death $[1,22]$. Nakagawa et al. [24] reduced the production of UA by the XO inhibitor allopurinol while simultaneously inhibiting the progression of hypertriglyceridaemia.

\section{Uric Acid in the development of inflammation}

High levels of UA can lead to systemic sterile inflammation and may also become a pro-inflammatory factor. The mainstream view is that high levels of UA form monosodium urate (MSU) around cells through extracellular sodium reactions. Apoptosis-associated speck-like protein containing a caspase-associated recruitment domain (ASC) recruits caspase- 1 and, together with NLR family pyrin domain containing 3 (NLRP3), forms NLRP3 inflammatory vesicles that convert MSU-produced pro-IL-1 into IL-1 $\beta$, which triggers the inflammatory response [25]. However, the distribution of NLRP3 in cells is relatively restricted. Its expression in the female reproductive system is found only in non-keratinized epithelial cells of the uterine cervix [26]. In addition, it has been reported that pregnant women with concurrent PE often have high levels of MSU, which can trigger placental inflammation through NLRP3 inflammatory vesicles and produce factors such as IL-1 $1 \beta$ to induce apoptosis in trophoblast cells [27].

In addition to promoting inflammation in the form of MSU crystals, soluble UA in adipocytes can also mediate lipid oxidation by activating mitogenic protein kinases such as p38 mitogen-activated protein kinase (p38 MAPK) and extracellular signal-regulated kinase $1 / 2$ (ERK1/2) through NADPH oxidase activation [28]. In other cells, this signalling pathway can also induce the production of various chemokines and inflammatory markers, including monocyte chemotactic protein 1 (MCP-1), C-reactive protein (CRP), IL-1, IL-6, IL-18, and tumour necrosis factor- $\alpha$ (TNF- $\alpha$ ), which trigger the disruption of lipid metabolism [29, 30].

UA serves as an end product of purine metabolism reflecting the metabolic state of the body, and it can maintain the level of oxidation in the body under physiological conditions. However, excessive accumulation of UA can cause damage to multiple systems throughout the body. In reproductive system diseases, although these mechanisms are still unclear, we currently believe that UA may be involved in key aspects of oxidative stress, inflammation, and metabolic disorders in vivo, leading to the development of various pathological conditions (Fig. 2).

\section{Hormone level effects on Uric Acid levels}

Reproductive hormones also affect serum UA levels. Although there is considerable disagreement on the issue of specific hormones and UA levels, the prevailing view is that high levels of testosterone are strongly associated with elevated serum UA levels and hyperuricaemia. Testosterone may induce functional alterations in the renal UA reabsorption system through increased expression of URAT1, sodium-coupled monocarboxylate transporter 1, and/or 2 (SMCT1 and/or 2) or GLUT9, among others [31]. Animal studies also suggest that testosterone may increase serum UA levels by inducing the hepatic metabolism of purine nucleotides [32]. High UA levels and hyperuricaemia are common in PCOS patients and are usually accompanied by hyperandrogenaemia [4]. Excessive androgen production by the ovaries and adrenal glands is an important cause of a large amount of follicle atresia, which ultimately leads to ovulation disorders in women with PCOS [33]. In addition to the conventional treatment of UA, the use of anti-androgenic contraceptives reduces serum UA levels in obese PCOS patients and significantly reduces the clinical severity [8]. The effect of serum UA on testosterone levels is still unknown. 


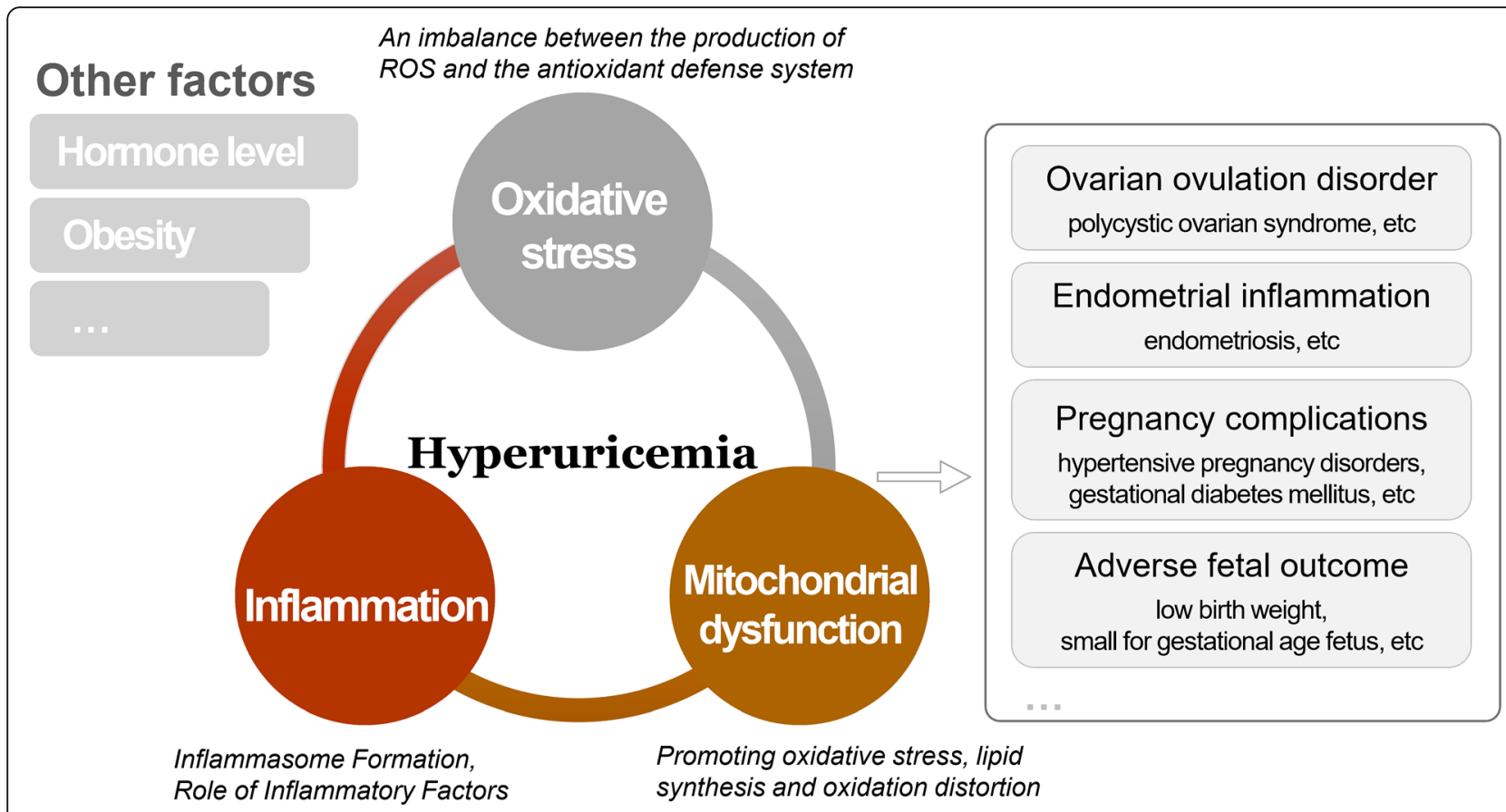

Fig. 2 Hyperuricemia is linked to female reproductive health, mainly through oxidative stress, inflammation and mitochondrial dysfunction

The link between oestradiol and UA is controversial. High UA levels are observed in menopausal women under normal conditions and may also be associated with postmenopausal insulin resistance (IR), obesity (BMI $\geq 25 \mathrm{~kg}$ / $\mathrm{m}^{2}$ ), and ethanol intake [34]. Hormone replacement therapy with oestrogen reduces serum UA levels in postmenopausal patients with hyperuricaemia [35]. These pieces of evidence suggest a potential effect of oestrogen. Oestrogen seems to increase the excretion of UA from the kidneys and intestines, and at the same time, it reduces the production of UA by inhibiting the $\mathrm{XO}$ system during hypoxia and stabilizing lipid metabolism [36-38]. However, it has also been suggested that the high prevalence of hyperuricaemia in older women is only associated with ageing and not with menopause [39]. Some studies have similarly shown opposing results [4, 40]. Larger samples are still needed for corroboration.

The relationship between follicle-stimulating hormone, luteinizing hormone and UA levels is also controversial. Few studies have reported a positive relationship between increased levels of follicle-stimulating hormone and luteinizing hormone and UA accumulation $[4,40]$. Notably, plasma sex hormone-binding globulin (SHBG) is significantly lower in postmenopausal patients with elevated serum UA levels [41]. Changes in hormones in patients with hyperuricaemia may also be associated with changes in their plasma SHBG levels. SHBG can also bind free androgens to reduce their levels and control their bioavailability to indirectly affect the UA concentration. Fujihara et al. [42] suggested that a lower concentration of SHBG
(46.5 nmol/L) was a predictor of hyperuricaemia, which may lead to reduced production of SHBG via induced inactivation of AMPK in the liver [43].

\section{Uric acid in polycystic ovarian syndrome (PCOS)}

Serum UA accumulation is closely related to ovarian ovulation disorders. PCOS is a common metabolic disease characterized by hyperandrogenism, oligo-ovulation, and polycystic ovarian morphology, often accompanied by an adverse clinical risk of miscarriage and many pregnancy complications [44]. Frequent abnormal lipid metabolism and abnormal glucose metabolism that accompany PCOS also increase the risk of cardiovascular disease, diabetes, and other chronic diseases [45]. Hyperuricaemia is one of the important characteristics observed in these patients. Several studies have shown that serum UA levels are significantly higher in PCOS patients than in non-PCOS women of normal reproductive age, especially in those patients with obesity, which is believed to be an important factor affecting UA concentrations in PCOS patients $[4$, 46]. Liu et al. [47] summarized the role of UA in the development of PCOS in patients, emphasizing its potential mechanisms in oxidative stress, inflammatory promotion, endothelial injury, and thrombosis in cardiovascular disease progression in these patients.

High serum UA levels in PCOS patients are closely related to androgen excess and IR. Androgens may increase serum UA levels by inducing hepatic metabolism of purine nucleotides and enhancing purine renewal in the kidney [32, 48]. The use of anti-androgenic 
contraceptives significantly reduces serum UA levels in these patients [8]. Hyperuricaemia is also an important marker of IR. Serum UA levels are negatively associated with insulin sensitivity $[49,50]$. PCOS patients with combined IR tend to have higher levels of insulin in the blood. High insulin levels not only reduce the renal excretion of UA but also increase the potential for androgen production [51, 52].

IR is prevalent in women with PCOS independent of obesity, which can also be observed in many patients with hyperuricaemia [53]. Possible mechanisms by which hyperuricaemia may cause or aggravate IR are as follows: (i) high UA levels reduce tissue phosphorylated protein kinase B (pAkt) levels, causing impairment of the protein kinase B/endothelial nitric oxide synthase (Akt/eNOS) signalling pathway and resulting in decreased nitric oxide (NO) production, which decreases blood flow to skeletal muscle and reduces its uptake of glucose [54]. Animal experiments have also found that NO induces IR and leads to impaired vasodilation in hyperuricaemic rats [55]. (ii) UA can form NLRP3 inflammatory vesicles and release various pro-inflammatory factors, which can impair insulin signalling. Animal experiments revealed that disruption of the NLRP3 gene in obese mice resulted in inactivation of the insulin phosphoinositide 3 kinase/protein kinase $\mathrm{B}$ (PI3K/Akt) pathway and ERK1/2, resulting in decreased cellular sensitivity to insulin $[56,57]$. Moreover, the activation of ERK1/2 downregulates the expression of peroxisome proliferator-activated receptor $\alpha$ in rat liver, which reduces fatty acid $\beta$-oxidation and triggers impaired fatty acid oxidation and triglyceride accumulation, ultimately causing obesity and hypertriglyceridaemia [58]. Obesity is an important factor affecting UA levels in PCOS; at the same time, elevated UA increases the risk of developing hypertriglyceridaemia [59]. (iii) In addition, certain effects of high levels of fatty acids in plasma can impair insulin secretion due to pancreatic $\beta$-cell dysfunction [60]. (iv) Finally, high levels of UA also reduce adiponectin levels and increase the risk of type 2 diabetes [61].

Hyperuricaemia in patients with PCOS was also observed to be accompanied by significant levels of oxidative stress, especially in the presence of obesity [46, 49]. These patients tend to have significant elevations in oxidative stress biomarkers, including NO, malondialdehyde, and many adaptive changes in antioxidative stress markers [62]. Malondialdehyde is a stable end product of lipid peroxidation, suggesting an imbalance in lipid oxidation. In this way, the unbalanced oxidation level caused by the accumulation of UA exacerbates the occurrence of inflammation. In the inflammatory state of PCOS, monocytes release more ROS due to hyperglycaemia, which then reactivates cytokines such as TNF- $\alpha$ and inflammatory transcription factors. Finally, in this vicious cycle, UA mediates the development of IR and hyperandrogenaemia [51].

\section{The potential link between Uric Acid, IL-1 $\beta$, and endometriosis}

Endometriosis is considered to be an inflammatory, immune, and haemorrhagic disease with the main clinical manifestations of dysmenorrhea, chronic pelvic pain, menstrual abnormalities, and infertility. Accumulating evidence suggests that IL-1 $\beta$ plays an important role in the development of endometriosis (Fig. 3). IL-1 $\beta$ is produced when UA forms inflammasomes (mentioned above). Serum IL-1 $\beta$ levels were significantly higher in women with deep infiltrating endometriosis than in normal women in the control group [63]. IL-1 $\beta$ may induce thymic stromal lymphopoietin secretion by promoting regulation upon activation of normal $\mathrm{T}$ cell expression and secreted factor mRNA expression, allowing monocytes and $\mathrm{T}$ cells to accumulate and activate Th2 immune responses, producing a local inflammatory response $[64,65]$. Akoum et al. [66] reported that oestrogen can synergize with IL-1 $\beta$ to enhance local inflammatory responses. On the one hand, the number of oestrogen receptors on macrophages in the peritoneal fluid is associated with the production of IL-1 $\beta$, and on the other hand, oestrogen promotes the secretion of MCP-1, which enhances the recruitment of macrophages [67]. In addition to pro-inflammatory effects, IL-1 $\beta$ plays a role in promoting angiogenesis and the proliferation of endometrial cells [68]. This may be related to the promotion of macrophage migration inhibitory factor synthesis by IL-1 $1 \beta$.

Women with endometriosis often have prolonged, severe pelvic pain that is not relieved by analgesic drugs. This may be because IL-1 $\beta$ increases brain-derived neurotrophic factor (BDNF) and the nerve injuryinducible protein 1 (Ninj1) through a signal transduction pathway mediated by c-Jun N-terminal kinase (JNK) and NF- $\mathrm{kB}$, which in turn stimulates the associated nerves and causes pelvic pain $[69,70]$. It has also been found that IL- $1 \beta$ increases the density of sensory nerve fibres and decreases the density of sympathetic nerve fibres [71]. In mice with endometriosis, the lesions were reduced in size and pain was relieved with significantly lower IL-1 $\beta$ levels following the use of NF- $\kappa$ B activation inhibitors such as norethindrone [72].

Up to approximately one-half of women with endometriosis have infertility [73]. It has been suggested that the imbalanced state of IL-1 $\beta$ and its decoy inhibitory receptors may contribute to infertility in patients with endometriosis. Higher concentrations of IL- $1 \beta$ and lower concentrations of IL-1 receptor 2 (decoy inhibitory receptor type 2 of IL-1) were observed in the peritoneal fluid of patients with endometriosis with infertility compared to normal women [74]. In addition, IL-1 $\beta$ at certain levels induces ovulation and inhibits endometrial metaplasia, which may be detrimental to embryo implantation and pregnancy maintenance in normal women and women with endometriosis, ultimately leading to infertility [75]. 


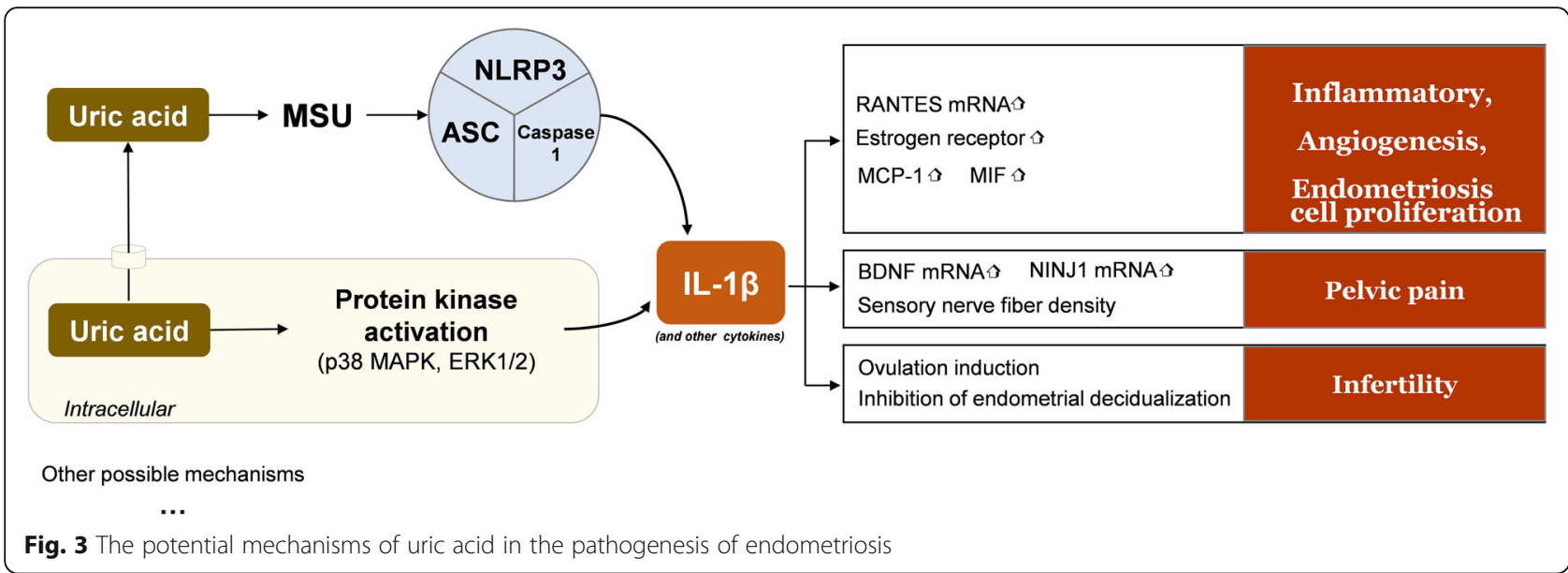

\section{Uric Acid and Pregnancy complications}

In the early stages of normal pregnancy, serum UA levels decrease due to increased plasma volume, increased renal clearance, and the urate excretion promoting effect of oestrogen. Serum UA stabilizes at a certain level during most of the second trimester. In late gestation, serum UA increases rapidly due to the excretion of foetal metabolites through the mother [76]. Almost half of women with hypertensive disorders of pregnancy (HDPs) or gestational diabetes mellitus (GDM) have significantly increased UA concentrations in pregnancy [6,7].

HDPs include four conditions: gestational hypertension, $\mathrm{PE}$, chronic hypertension and chronic hypertension with superimposed PE. PE is a severe HDP that begins with impaired maternal uteroplacental vascular formation. If not treated early, it may progress to eclampsia as well as maternal and foetal in utero growth restriction and death. Many pregnant women with PE commonly have elevated UA levels or even hyperuricaemia. There are multiple potential sources of increased UA in PE, the main ones are as follows [77, 78]: (i) Overproduction of vasoconstrictor substances leads to decreased renal UA secretion, and decreased renal blood flow and glomerular filtration decrease UA clearance. (ii) Poor trophoblast invasiveness. Hypoxia stimulates massive production of lactic acid, leading to acidosis that can impede UA secretion. (iii) Apoptotic homeostasis occurs when trophoblast cells are stimulated by hypoxia and oxidative stress. UA, a major product of purine metabolism, will be produced in increased amounts. (iv) Under these conditions, increased $\mathrm{XO} / \mathrm{XDH}$ activity, which is involved in purine metabolism, directly increases the production of UA.

Similarly, in PE patients, high UA levels affect the normal function of blood vessels and the placenta mainly through oxidative stress and inflammation. UA induces oxidative stress, which is considered to be a key link in PE. On the one hand, oxidative products promote the production of vasoconstrictive substances, activating the local renin-angiotensin system in human endothelial vascular cells including angiotensin II. On the other hand, it leads to decreased production and bioavailability of diastolic substances (e.g., NO, prostacyclin) inducing endothelial dysfunction [79]. Doughan et al. [20]. proposed a model of angiotensin II-induced mitochondrial dysfunction. Angiotensin II activates NADPH oxidase through protein kinase $\mathrm{C}$ (PKC)-dependent activation, leading to ROS production and mitochondrial dysfunction, which in turn further activates NADPH oxidase, resulting in increased cellular oxidation levels and decreased NO bioavailability. Among these, the effect of UA on NO production not only affects the maternal vascular system but is also crucial for changes in trophoblast cells during placental development, which may be involved in the development of HDPs and adverse foetal outcomes [30]. In hyperuricaemic rats, UA reduces endothelial $\mathrm{NO}$ synthase activity to limit $\mathrm{NO}$ availability and upregulates cyclooxygenase-2 (COX-2) expression by increasing the production of the vasoconstrictor thromboxane, impairing placental perfusion and inhibiting foetal growth [80].

High UA levels also have a profound effect on endothelial cell migration, proliferation, and apoptosis. UA significantly inhibited serum-induced proliferation in human umbilical vein endothelial cells and their migration [30]. At the same time, proliferation and apoptosis of vascular smooth muscle cells in an inflammatory state cause vascular remodelling and ultimately widespread endothelial cell dysfunction [29]. UA-induced inflammation may be widely relevant. In addition to the observation of increased multiple inflammatory markers, Stodle et al. [81] also reported enhanced NLRP3 inflammatory vesicle activation caused by UA crystals in the trophoblastic layer of the placental syncytium in PE, highlighting an important link to inflammation.

GDM is a type of diabetes that is not present before pregnancy and occurs during pregnancy. Although it 
may disappear after delivery, women who have had GDM are at an increased risk of developing type 2 diabetes later. Early pregnancy UA levels can be used to some extent as a secondary predictor of GDM and may be partially involved in the development of GDM [82]. High UA levels that persist after delivery are also a highrisk factor for type 2 diabetes mellitus. It was found that patients with GDM have active purine metabolism and higher levels of UA in serum and amniotic fluid [83, 84]. The latter was also positively associated with BMI and glucose levels [85]. Possible mechanisms by which high serum UA levels lead to glucose metabolism disorders and IR include mitochondrial dysfunction, lipid oxidative stress, inflammatory mediator production such as TNF$\alpha$, and reduced lipocalin levels [86-88].

\section{Uric Acid and adverse foetal outcomes}

Serum UA in some cases can directly affect foetal growth. In addition to oxidative stress and inflammation affecting the vasculature and placenta, as mentioned earlier, other causes include the following: (i) The direct toxic effects of UA on foetal growth. (ii) Elevated UA levels can affect the transport of nutrients. For example, UA-induced oxidative stress can inhibit mammalian target of rapamycin (mTOR) signalling and reduce amino acid transport to the foetus [89]. (iii) Finally, elevated UA levels can also affect hormone levels in foetuses, especially growth hormones [90].

Serum UA levels have also been associated with the risk of preterm birth in pregnant women. In a casecontrol study by Roberts et al. [91], hyperuricaemia was found to increase the risk of preterm delivery and low birth weight of the infant. Pregnant women with PE who had low to moderate levels of UA concentrations at admission had an increased likelihood of prolonged pregnancy [92]. Lower foetal birth weight may also be associated with preterm delivery, where the shortened gestation time allows the foetus to be born before it is fully developed in utero.

The relationship between UA and inflammation has already been mentioned above, including the involvement of multiple inflammatory factors and the formation of inflammatory vesicles. Several studies have found that elevated IL- $1 \beta$ levels may increase the risk of preterm birth. The evidence that IL-1 $\beta$ increases the risk of preterm birth is as follows: (i) IL- $1 \beta$ expression is increased in the amnion, chorionic villus, cervix, and myometrium after normal delivery [93]. IL-1 $\beta$ can induce uterine smooth muscle contraction by increasing COX-2 expression and promoting prostaglandin synthesis [80]. (ii) IL$1 \beta$ can enhance local progesterone metabolism in some cells by regulating $20 \alpha$-hydroxysteroid dehydrogenase activity, which decreases local progesterone levels to activate uterine muscle [94]. (iii) Animal studies have demonstrated that IL-1 $\beta$ alone can induce preterm labour, while the use of IL- $1 \beta$ receptor antagonists can prevent this effect [95]. (iv) IL-1 receptor antagonist has a linear relationship with IL-1 $\beta$, while studies have found a high predictive value of cervicovaginal fluid and blood IL-1 receptor antagonist levels for preterm birth risk [96, 97]. Thus, we speculate that elevated UA levels may indirectly affect the course of pregnancy and increase the risk of preterm delivery.

Elevated serum UA levels are considered to be a predictor of maternal and infant complications, so early measurement of serum UA may be beneficial in the diagnostic treatment of this clinical syndrome. The sensitivity from the study by Bellos et al. [5] for predicting adverse perinatal outcomes in patients with PE with high UA levels ranged from 67.3 to $82.7 \%$, and the specificity ranged from 47.7 to $70.7 \%$. In women with PE/eclampsia, high UA levels are considered in most studies to be a good predictor of foetal/neonatal complications. A cohort study by Le et al. [98] found that serum UA levels at a threshold of $393 \mathrm{mmol} / \mathrm{l}$ may be predictive of adverse outcomes such as preterm birth, low Apgar scores, intrauterine growth restriction, and neonatal death in women with PE.

Amniotic fluid UA monitoring is also considered to be of value in predicting foetal growth. In early gestation, amniotic fluid is mainly derived from the plasma component of the embryo. As the organs of the embryo begin to mature and develop, the metabolites of the foetus gradually increase, as do the levels of amniotic fluid UA. It has been suggested that amniotic fluid UA is an important predictor of infant birth weight in mid-gestation [99]. In addition, amniotic fluid UA also reflects maternal pre-pregnancy BMI, which correlates with maternal nutritional status and oxidative stress levels [100]. In late gestation, the UA concentration in maternal amniotic fluid is significantly higher than that in maternal venous serum or cord serum, which may be determined mainly by the urine produced by foetal excretion. The amniotic fluid UA concentration may also be an indicator of foetal maturity due to its ability to reflect the maturity of the kidney. Harrison [101] used amniotic fluid UA to detect up to $79 \%$ of mature foetuses. Animal studies by Koski et al. [102] confirmed the relationship between elevated amniotic fluid UA levels and foetal weight, emphasizing that the amniotic fluid composition may be predictive of foetal growth and metabolic maturity.

\section{Conclusion and future perspectives}

In this review, we tried to summarize the relationship between UA and female reproductive diseases, focusing on some of the characteristics of UA and its possible mechanisms in the development of PCOS, endometriosis, pregnancy complications, and other diseases. We 
believe that there is a close interaction between abnormal UA levels in patients with these diseases and various symptoms and long-term complications. We suspect that there is a certain correlation between UA levels and oxidative stress, inflammation, mitochondrial dysfunction, and so on. These factors influence and promote each other, forming a vicious circle. We hope our results can be helpful in showing possibilities for potential prevention, treatment, and prognostic assessment.

Our understanding of the role of UA in the reproductive system is also growing as more literature is added. Serum UA levels have been proposed to predict the occurrence of $\mathrm{PE}$ and adverse maternal and foetal outcomes [5]. A model containing UA and hypoxanthine has also been constructed to diagnose the prognosis of minimal/mild endometriosis with a sensitivity of $66.7 \%$ and specificity of $90.0 \%$ [103]. In some trials targeting low seminal plasma UA levels in infertile male patients, antioxidant protocols have been used with overall positive results. Anti-androgen drugs in PCOS patients also significantly alleviated the state of high UA levels. Nevertheless, more well-designed trials are needed to assess the potential of these regimens.

\section{Abbreviations}

UA: Uric Acid; PCOS: Polycystic Ovary Syndrome; XOR: Xanthine Oxidoreductase; XO: Xanthine Oxidase; XDH: Xanthine Dehydrogenase; ROS: Reactive Oxygen Species; URAT1: Urate Transporter 1; OAT4: Organic Anion Transporter 4; GLUT9: Glucose Transporter 9; PE: Pre-eclampsia; NOX4: NADPH Oxidase 4; AMPK: AMP-activated Kinase; AMPD: AMP Deaminase; MSU: Monosodium Urate; NLRP3: NLR Family Pyrin Domain Containing 3; p38 MAPK: P38 Mitogen-Activated Protein Kinase; ERK1/ 2: Extracellular Signal-Regulated Kinase 1/2; MCP-1: Monocyte Chemotactic Protein 1; CRP: C-Reactive Protein; TNF-a: Tumor Necrosis Factor a; SMCT1 and/or 2: Sodium-Coupled Monocarboxylate Transporter 1 and/or 2; IR: Insulin Resistance; SHBG: Sex Hormone-binding Globulin; pAkt: Phosphorylated Protein Kinase B; Akt: Protein Kinase B; eNOS: Endothelial Nitric Oxide Synthase; NO: Nitric Oxide; PI3K: Phosphoinositide 3 Kinase; HDPs: Hypertensive Disorders of Pregnancy; GDM: Gestational Diabetes Mellitus; BDNF: Brain-Derived Neurotrophic Factor; Ninj1: Nerve Injury-Inducible Protein 1; JNK: C-Jun N-Terminal Kinase; PKC: Protein kinase C; COX-2: Cyclooxygenase-2; mTOR: Mammalian Target of Rapamycin
\end{abstract}

\section{Acknowledgements}

None.

\section{Authors' contributions}

L.S. M. designed the manuscript. H.Y. Y. participated in the collection of literature. J.H. H. and W.Y X. drafted and finished the manuscript equally. All authors read and approved the final manuscript.

\section{Funding}

This work was supported by the National Natural Science Foundation of China (No.82001503), and the China Postdoctoral Science Foundation (2020M671760).

Availability of data and materials: Not applicable.

\section{Declarations}

Ethics approval and consent to participate

Not applicable.

\section{Consent for publication}

Written informed consent for publication was obtained from all participants.

\section{Competing interests}

The authors declare that they have no competing interests.

Received: 17 March 2021 Accepted: 18 April 2021

Published online: 27 April 2021

\section{References}

1. Sautin YY, Johnson RJ. Uric acid: the oxidant-antioxidant paradox. Nucleosides Nucleotides Nucleic Acids. 2008. doi:https://doi.org/10.1080/152 57770802138558

2. Richette P, Perez-Ruiz F, Doherty M, et al. Improving cardiovascular and renal outcomes in gout: what should we target? Nat Rev Rheumatol. 2014. doi:https://doi.org/10.1038/nrrheum.2014.124.

3. Battelli MG, Bortolotti $M$, Polito $L$, Bolognesi $A$. The role of xanthine oxidoreductase and uric acid in metabolic syndrome. Biochim Biophys Acta Mol Basis Dis. 2018. doi:https://doi.org/10.1016/j.bbadis.2018.05.003.

4. Mu L, Pan J, Yang L, et al. Association between the prevalence of hyperuricemia and reproductive hormones in polycystic ovary syndrome. Reproductive Biology Endocrinology. 2018. doi:https://doi.org/10.1186/s12 958-018-0419-x.

5. Bellos I, Pergialiotis V, Loutradis D, Daskalakis G. The prognostic role of serum uric acid levels in preeclampsia: A meta-analysis. J Clin Hypertens (Greenwich). 2020. doi:https://doi.org/10.1111/jch.13865.

6. Weissgerber TL, Milic NM, Turner ST, et al. Uric Acid: A Missing Link Between Hypertensive Pregnancy Disorders and Future Cardiovascular Disease? Mayo Clin Proc. 2015; doi:https://doi.org/10.1016/j.mayocp.2015.05.020.

7. Laughon SK, Catov J, Provins T, et al. Elevated first-trimester uric acid concentrations are associated with the development of gestational diabetes. Am J Obstet Gynecol. 2009. doi:https://doi.org/10.1016/j.ajog.2009. 06.065 .

8. Luque-Ramirez M, Alvarez-Blasco F, Uriol Rivera MG, Escobar-Morreale HF. Serum uric acid concentration as non-classic cardiovascular risk factor in women with polycystic ovary syndrome: effect of treatment with ethinylestradiol plus cyproterone acetate versus metformin. Hum Reprod. 2008. doi:https://doi.org/10.1093/humrep/den095

9. Chaudhary K, Malhotra K, Sowers J, Aroor A. Uric Acid - key ingredient in the recipe for cardiorenal metabolic syndrome. Cardiorenal Med. 2013. doi: https://doi.org/10.1159/000355405.

10. Glantzounis GK, Tsimoyiannis EC, Kappas AM, Galaris DA. Uric acid and oxidative stress. Curr Pharm Des. 2005. doi:https://doi.org/10.2174/1381612 05774913255

11. Maiuolo J, Oppedisano F, Gratteri S, et al. Regulation of uric acid metabolism and excretion. Int J Cardiol. 2016. doi:https://doi.org/10.1016/j. ijcard.2015.08.109.

12. Xu L, Shi Y, Zhuang S, Liu N. Recent advances on uric acid transporters. Oncotarget. 2017. doi:https://doi.org/10.18632/oncotarget.20135.

13. Cassano $E$, Tosto $L$, Balestrieri $M$, et al. Antioxidant defense in the follicular fluid of water buffalo. Cell Physiol Biochem. 1999. doi:https://doi.org/10.11 59/000016307.

14. Wen X, Perrett $D$, Jones $N$, et al. High follicular fluid adenosine levels may be pivotal in the metabolism and recycling of adenosine nucleotides in the human follicle. Metabolism. 2010. doi:https://doi.org/10.1016/j.metabol.2009. 09.037.

15. Abuja PM. Ascorbate prevents prooxidant effects of urate in oxidation of human low density lipoprotein. FEBS Lett. 1999. doi:https://doi.org/10.1016/ s0014-5793(99)00231-8.

16. Tonnies E, Trushina E. Oxidative, Stress. Synaptic Dysfunction, and Alzheimer's Disease. J Alzheimers Dis. 2017. doi:https://doi.org/10.3233/JAD-161088.

17. Bergamini CM, Gambetti S, Dondi A, Cervellati C. Oxygen, reactive oxygen species and tissue damage. Curr Pharm Des. 2004; https://doi.org/10.21 74/1381612043384664 
18. Bannigida DM, Nayak BS, Vijayaraghavan R. Insulin resistance and oxidative marker in women with PCOS. Arch Physiol Biochem. 2020. doi:https://doi. org/10.1080/13813455.2018.1499120.

19. Aouache R, Biquard L, Vaiman D, Miralles F. Oxidative Stress in Preeclampsia and Placental Diseases. Int J Mol Sci. 2018. doi:https://doi.org/10.3390/ijms1 9051496.

20. Doughan AK, Harrison DG, Dikalov SI. Molecular mechanisms of angiotensin II-mediated mitochondrial dysfunction: linking mitochondrial oxidative damage and vascular endothelial dysfunction. Circ Res. 2008. doi:https://doi. org/10.1161/CIRCRESAHA.107.162800.

21. Lanaspa MA, Sanchez-Lozada LG, Choi YJ, et al. Uric acid induces hepatic steatosis by generation of mitochondrial oxidative stress: potential role in fructose-dependent and -independent fatty liver. J Biol Chem. 2012. doi: https://doi.org/10.1074/jbc.M112.399899.

22. Lima WG, Martins-Santos ME, Chaves VE. Uric acid as a modulator of glucose and lipid metabolism. Biochimie. 2015. doi:https://doi.org/10.1016/j. biochi.2015.06.025

23. Cicerchi C, Li N, Kratzer J, et al. Uric acid-dependent inhibition of AMP kinase induces hepatic glucose production in diabetes and starvation: evolutionary implications of the uricase loss in hominids. FASEB J. 2014. doi: https://doi.org/10.1096/fj.13-243634

24. Nakagawa T, Hu H, Zharikov S, et al. A causal role for uric acid in fructoseinduced metabolic syndrome. Am J Physiol Renal Physiol. 2006. doi:https:// doi.org/10.1152/ajprenal.00140.2005

25. Ghaemi-Oskouie F, Shi Y. The role of uric acid as an endogenous danger signal in immunity and inflammation. Curr Rheumatol Rep. 2011. doi:https:// doi.org/10.1007/s11926-011-0162-1

26. Petrilli V, Dostert C, Muruve DA, Tschopp J. The inflammasome: a danger sensing complex triggering innate immunity. Curr Opin Immunol. 2007. doi: https://doi.org/10.1016/j.coi.2007.09.002.

27. Brien ME, Duval C, Palacios J, et al. Uric Acid Crystals Induce Placental Inflammation and Alter Trophoblast Function via an IL-1-Dependent Pathway: Implications for Fetal Growth Restriction. J Immunol. 2017. doi: https://doi.org/10.4049/jimmunol.1601179.

28. Sautin YY, Nakagawa T, Zharikov S, Johnson RJ. Adverse effects of the classic antioxidant uric acid in adipocytes: NADPH oxidase-mediated oxidative/ nitrosative stress. Am J Physiol Cell Physiol. 2007. doi:https://doi.org/10.11 52/ajpcell.00600.2006.

29. Kanellis J, Watanabe S, Li JH, et al. Uric acid stimulates monocyte chemoattractant protein-1 production in vascular smooth muscle cells via mitogen-activated protein kinase and cyclooxygenase-2. Hypertension. 2003. doi:https://doi.org/10.1161/01.HYP.0000072820.07472.3B.

30. Kang DH, Park SK, Lee IK, Johnson RJ. Uric acid-induced C-reactive protein expression: implication on cell proliferation and nitric oxide production of human vascular cells. J Am Soc Nephrol. 2005. doi:https://doi.org/10.1681/A SN.2005050572.

31. Hosoyamada M, Takiue $Y$, Shibasaki T, Saito $H$. The effect of testosterone upon the urate reabsorptive transport system in mouse kidney. Nucleosides Nucleotides Nucleic Acids. 2010. doi:https://doi.org/10.1080/15257770.2010.4 94651.

32. Pizzichini M, Di Stefano A, Resconi $G$, et al. Influence of testosterone on purine nucleotide turnover in rat kidney. Horm Metab Res. 1990. doi:https:// doi.org/10.1055/s-2007-1004914.

33. Jonard S, Dewailly D. The follicular excess in polycystic ovaries, due to intraovarian hyperandrogenism, may be the main culprit for the follicular arrest. Hum Reprod Update. 2004. doi:https://doi.org/10.1093/humupd/dmh010.

34. Koga M, Saito $H$, Mukai $M$, et al. Factors contributing to increased serum urate in postmenopausal Japanese females. Climacteric. 2009. doi:https:// doi.org/10.1080/13697130802607719.

35. Sumino $\mathrm{H}$, Ichikawa $\mathrm{S}$, Kanda $\mathrm{T}$, et al. Reduction of serum uric acid by hormone replacement therapy in postmenopausal women with hyperuricaemia. The Lancet. 1999. doi:https://doi.org/10.1016/s0140-673 6(99)92381-4.

36. Takiue $Y$, Hosoyamada M, Kimura M, Saito $H$. The effect of female hormones upon urate transport systems in the mouse kidney. Nucleosides Nucleotides Nucleic Acids. 2011. doi:https://doi.org/10.1080/15257770.2010.551645.

37. Fantozzi ET, Breithaupt-Faloppa AC, Ricardo-da-Silva FY, et al. Estradiol mediates the long-lasting lung inflammation induced by intestinal ischemia and reperfusion. J Surg Res. 2018. doi:https://doi.org/10.1016/j.jss.2017.07.038.

38. Budhiraja R, Kayyali US, Karamsetty M, et al. Estrogen modulates xanthine dehydrogenase/xanthine oxidase activity by a receptor-independent mechanism. Antioxid Redox Signal. 2003. doi:https://doi.org/10.1089/1523 08603770380007.

39. Krishnan E, Bennett M, Chen L. Aging, not menopause, is associated with higher prevalence of hyperuricemia among older women. Menopause. 2014. doi:https://doi.org/10.1097/GME.0000000000000230.

40. Jung JH, Song $\mathrm{GG}$, Lee $\mathrm{YH}$, et al. Serum uric acid levels and hormone therapy type: a retrospective cohort study of postmenopausal women. Menopause. 2018. doi:https://doi.org/10.1097/GME.0000000000000953.

41. Stöckl D, Döring A, Thorand B, et al. Reproductive factors and serum uric acid levels in females from the general population: the KORA F4 study. PLoS One. 2012. doi:https://doi.org/10.1371/journal.pone.0032668.

42. Fujihara $Y$, Hamanoue $N$, Akehi $Y$, et al. Relatively low sex hormone-binding globulin concentration is a risk factor for hyperuricemia in middle-aged Japanese men. Obesity Science Practice. 2020. doi:https://doi.org/10.1002/osp4.413.

43. Vila L, Roglans $N$, Alegret $M$, et al. Suppressor of cytokine signaling-3 (SOCS3) and a deficit of serine/threonine (Ser/Thr) phosphoproteins involved in leptin transduction mediate the effect of fructose on rat liver lipid metabolism. Hepatology. 2008. doi:https://doi.org/10.1002/hep.22523.

44. Bahri Khomami M, Joham AE, Boyle JA, et al. Increased maternal pregnancy complications in polycystic ovary syndrome appear to be independent of obesity-A systematic review, meta-analysis, and meta-regression. Obes Rev. 2019. doi:https://doi.org/10.1111/obr.12829.

45. Osibogun $\mathrm{O}$, Ogunmoroti O, Michos ED. Polycystic ovary syndrome and cardiometabolic risk: Opportunities for cardiovascular disease prevention. Trends Cardiovasc Med. 2020. doi:https://doi.org/10.1016/j.tcm.2019.08.010.

46. Durmus U, Duran C, Ecirli S. Visceral adiposity index levels in overweight and/or obese, and non-obese patients with polycystic ovary syndrome and its relationship with metabolic and inflammatory parameters. J Endocrinol Invest. 2017. doi:https://doi.org/10.1007/s40618-016-0582-X.

47. Liu YN, Luo H, Che $\mathrm{X}$, et al. Uric acid metabolism in polycystic ovary syndrome. Clin Chim Acta. 2021. doi:https://doi.org/10.1016/j.cca.2021.02.009.

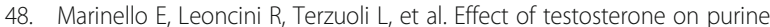
nucleotide metabolism in rat liver. Horm Metab Res. 2004. doi:https://doi. org/10.1055/s-2004-825923.

49. Desai V, Prasad NR, Manohar SM, et al. Oxidative stress in non-obese women with polycystic ovarian syndrome. J Clin Diagn Res. 2014. doi: https://doi.org/10.7860/JCDR/2014/8125.4530.

50. Li L, Zhang J, Zeng J, et al. Proteomics analysis of potential serum biomarkers for insulin resistance in patients with polycystic ovary syndrome. Int J Mol Med. 2020. doi:https://doi.org/10.3892/ijmm.2020.4522.

51. Qu J, Wang Y, Wu X, et al. Insulin resistance directly contributes to androgenic potential within ovarian theca cells. Fertil Steril. 2009. doi: https://doi.org/10.1016/j.fertnstert.2008.02.167.

52. Quiñones Galvan A, Natali A, Baldi S, et al. Effect of insulin on uric acid excretion in humans. Am J Physiol. 1995. doi:https://doi.org/10.1152/a jpendo.1995.268.1.E1.

53. Cassar S, Misso ML, Hopkins WG, et al. Insulin resistance in polycystic ovary syndrome: a systematic review and meta-analysis of euglycaemichyperinsulinaemic clamp studies. Hum Reprod. 2016. doi:https://doi.org/10.1 093/humrep/dew243.

54. Lee SJ, Oh BK, Sung KC. Uric acid and cardiometabolic diseases. Clin Hypertens. 2020. doi:https://doi.org/10.1186/s40885-020-00146-y.

55. Choi YJ, Yoon Y, Lee KY, et al. Uric acid induces endothelial dysfunction by vascular insulin resistance associated with the impairment of nitric oxide synthesis. FASEB J. 2014. doi:https://doi.org/10.1096/fj.13-247148.

56. Vandanmagsar B, Youm YH, Ravussin A, et al. The NLRP3 inflammasome instigates obesity-induced inflammation and insulin resistance. Nat Med. 2011. doi:https://doi.org/10.1038/nm.2279.

57. MacLaren R, Cui W, Simard S, Cianflone K. Influence of obesity and insulin sensitivity on insulin signaling genes in human omental and subcutaneous adipose tissue. J Lipid Res. 2008. doi:https://doi.org/10.1194/jlr.M700199-JLR200.

58. Li JM, Li YC, Kong LD, Hu QH. Curcumin inhibits hepatic protein-tyrosine phosphatase $1 \mathrm{~B}$ and prevents hypertriglyceridemia and hepatic steatosis in fructose-fed rats. Hepatology. 2010. doi:https://doi.org/10.1002/hep.23524.

59. Kuwabara M, Borghi C, Cicero AFG, et al. Elevated serum uric acid increases risks for developing high LDL cholesterol and hypertriglyceridemia: A fiveyear cohort study in Japan. Int J Cardiol. 2018. doi:https://doi.org/10.1016/j. ijcard.2018.03.045

60. Bergman RN, Ader M. Free fatty acids and pathogenesis of type 2 diabetes mellitus. Trends Endocrinol Metab. 2000. doi:https://doi.org/10.1016/s1043-2 760(00)00323-4. 
61. Kishida K, Funahashi T, Shimomura I. Adiponectin as a routine clinical biomarker. Best Pract Res Clin Endocrinol Metab. 2014. doi:https://doi.org/1 0.1016/j.beem.2013.08.006.

62. Mohammadi M. Oxidative Stress and Polycystic Ovary Syndrome: A Brief Review. Int J Prev Med. 2019. doi:https://doi.org/10.4103/ijpvm.IJPVM_ $576 \_17$.

63. Lambert S, Santulli P, Chouzenoux S, et al. [Endometriosis: increasing concentrations of serum interleukin-1 $\beta$ and interleukin-1sRII is associated with the deep form of this pathology]. J Gynecol Obstet Biol Reprod (Paris). 2014. doi:https://doi.org/10.1016/j.jgyn.2014.06.014.

64. Urata $Y$, Osuga $Y$, Izumi $G$, et al. Interleukin-1 beta stimulates the secretion of thymic stromal lymphopoietin (TSLP) from endometrioma stromal cells: possible involvement of TSLP in endometriosis. Hum Reprod. 2012. doi: https://doi.org/10.1093/humrep/des291.

65. Lebovic DI, Chao VA, Martini JF, Taylor RN. IL-1 beta induction of RANTES (regulated upon activation, normal T cell expressed and secreted) chemokine gene expression in endometriotic stromal cells depends on a nuclear factor-kappaB site in the proximal promoter. J Clin Endocrinol Metab. 2001. doi:https://doi.org/10.1210/jcem.86.10.7890.

66. Akoum A, Lemay A, Maheux R. Estradiol and interleukin-1 beta exert a synergistic stimulatory effect on the expression of the chemokine regulated upon activation, normal T cell expressed, and secreted in endometriotic cells. J Clin Endocrinol Metab. 2002. doi:https://doi.org/10.1210/ jc.2002-020106.

67. Akoum A, Jolicoeur C, Boucher A. Estradiol amplifies interleukin-1-induced monocyte chemotactic protein-1 expression by ectopic endometrial cells of women with endometriosis. J Clin Endocrinol Metab. 2000. doi:https://doi. org/10.1210/jcem.85.2.6348.

68. Bilotas M, Meresman G, Buquet R, et al. Effect of vascular endothelial growth factor and interleukin-1 beta on apoptosis in endometrial cell cultures from patients with endometriosis and controls. J Reprod Immunol. 2010. doi:https://doi.org/10.1016/j.jri.2009.12.002.

69. Yu J, Francisco AMC, Patel BG, et al. IL-1beta Stimulates Brain-Derived Neurotrophic Factor Production in Eutopic Endometriosis Stromal Cell Cultures: A Model for Cytokine Regulation of Neuroangiogenesis. Am J Pathol. 2018. doi:https://doi.org/10.1016/j.ajpath.2018.06.011.

70. Miyashita M, Koga K, Takeuchi A, et al. Expression of Nerve Injury-Induced Protein1 (Ninj1) in Endometriosis. Reprod Sci. 2019. doi:https://doi.org/10.11 77/1933719118806395

71. Arnold J, Vercellino GF, Chiantera V, et al. Neuroimmunomodulatory alterations in non-lesional peritoneum close to peritoneal endometriosis. Neuroimmunomodulation. 2013. doi:https://doi.org/10.1159/000342163.

72. Wei $X$, Shao X. Nobiletin alleviates endometriosis via down-regulating NFkappaB activity in endometriosis mouse model. Biosci Rep. 2018. doi:https:// doi.org/10.1042/BSR20180470.

73. Sensky TE, Liu DT. Endometriosis: associations with menorrhagia, infertility and oral contraceptives. Int J Gynaecol Obstet. 1980. doi:https://doi.org/10.1 002/j.1879-3479.1980.tb00210.x

74. Akoum A, Al-Akoum M, Lemay A, et al. Imbalance in the peritoneal levels of interleukin 1 and its decoy inhibitory receptor type II in endometriosis women with infertility and pelvic pain. Fertil Steril. 2008. doi:https://doi. org/10.1016/j.fertnstert.2007.06.019.

75. Yu J, Berga SL, Zou W, Taylor RN. Interleukin-1beta inhibits estrogen receptor-alpha, progesterone receptors $A$ and $B$ and biomarkers of human endometrial stromal cell differentiation: implications for endometriosis. Mol Hum Reprod. 2019. doi:https://doi.org/10.1093/molehr/gaz045.

76. Carter J, Child A. Serum uric acid levels in normal pregnancy. Aust. N. Z. J Obstet Gynaecol. 1989. doi:https://doi.org/10.1111/j.1479-828x.1989.tb01751.x.

77. Khaliq OP, Konoshita T, Moodley J, Naicker T. The Role of Uric Acid in Preeclampsia: Is Uric Acid a Causative Factor or a Sign of Preeclampsia? Curr Hypertens Rep. 2018. doi:https://doi.org/10.1007/s11906-018-0878-7.

78. Bainbridge SA, Roberts JM. Uric acid as a pathogenic factor in preeclampsia. Placenta. 2008. doi:https://doi.org/10.1016/j.placenta.2007.11.001

79. Incalza MA, D'Oria $R$, Natalicchio A, et al. Oxidative stress and reactive oxygen species in endothelial dysfunction associated with cardiovascular and metabolic diseases. Vascul Pharmacol. 2018. doi:https://doi.org/10.1016/ j.vph.2017.05.005.

80. Kang DH, Nakagawa $T$, Feng $L$, et al. A role for uric acid in the progression of renal disease. J Am Soc Nephrol. 2002. doi:https://doi.org/10.1097/01.asn. $0000034910.58454 . f d$.
81. Stodle GS, Silva GB, Tangeras LH, et al. Placental inflammation in preeclampsia by Nod-like receptor protein (NLRP)3 inflammasome activation in trophoblasts. Clin Exp Immunol. 2018. doi:https://doi.org/1 $0.1111 /$ cei. 13130 .

82. C R, Samal S, Ghose S. Association of Elevated first Trimester Serum Uric Acid Levels with Development of GDM. J Clin Diagn Res. 2014. doi:https:// doi.org/10.7860/jcdr/2014/8063.5226.

83. Leng J, Wang L, Wang J, et al. Uric acid and diabetes risk among Chinese women with a history of gestational diabetes mellitus. Diabetes Res Clin Pract. 2017. doi:https://doi.org/10.1016/j.diabres.2017.09.015.

84. Moleda P, Fronczyk A, Safranow K, Majkowska L. Is Uric Acid a Missing Link between Previous Gestational Diabetes Mellitus and the Development of Type 2 Diabetes at a Later Time of Life? PLoS One. 2016. doi:https://doi. org/10.1371/journal.pone.0154921.

85. Pleskacova A, Bartakova V, Chalasova K, et al. Uric Acid and Xanthine Levels in Pregnancy Complicated by Gestational Diabetes Mellitus-The Effect on Adverse Pregnancy Outcomes. Int J Mol Sci. 2018. doi:https://doi.org/10.33 90/ijms19113696.

86. Lanaspa MA, Cicerchi C, Garcia G, et al. Counteracting roles of AMP deaminase and AMP kinase in the development of fatty liver. PLoS One 2012. doi:https://doi.org/10.1371/journal.pone.0048801.

87. Kanety H, Feinstein R, Papa MZ, et al. Tumor necrosis factor alpha-induced phosphorylation of insulin receptor substrate-1 (IRS-1). Possible mechanism for suppression of insulin-stimulated tyrosine phosphorylation of IRS-1. J Biol Chem. 1995. doi:https://doi.org/10.1074/jbc.270.40.23780.

88. Baldwin W, McRae S, Marek G, et al. Hyperuricemia as a mediator of the proinflammatory endocrine imbalance in the adipose tissue in a murine model of the metabolic syndrome. Diabetes. 2011. doi:https://doi.org/10.233 7/db10-0916.

89. Martino J, Sebert S, Segura MT, et al. Maternal Body Weight and Gestational Diabetes Differentially Influence Placental and Pregnancy Outcomes. J Clin Endocrinol Metab. 2016. doi:https://doi.org/10.1210/jc.2015-2590.

90. Luo ZC, Bilodeau JF, Nuyt AM, et al. Perinatal Oxidative Stress May Affect Fetal Ghrelin Levels in Humans. Sci Rep. 2015. doi:https://doi.org/10.1038/ srep17881.

91. Roberts JM, Bodnar LM, Lain KY, et al. Uric acid is as important as proteinuria in identifying fetal risk in women with gestational hypertension. Hypertension. 2005. doi:https://doi.org/10.1161/01.Hyp. 0000188703.27002 .14

92. Urato AC, Bond B, Craigo SD, et al. Admission uric acid levels and length of expectant management in preterm preeclampsia. J Perinatol. 2012. doi: https://doi.org/10.1038/jp.2011.187.

93. Osman I, Young A, Ledingham MA, et al. Leukocyte density and proinflammatory cytokine expression in human fetal membranes, decidua, cervix and myometrium before and during labour at term. Mol Hum Reprod. 2003. doi:https://doi.org/10.1093/molehr/gag001.

94. Roberson $\mathrm{AE}$, Hyatt $\mathrm{K}$, Kenkel $\mathrm{C}$, et al. Interleukin 1 beta regulates progesterone metabolism in human cervical fibroblasts. Reprod Sci. 2012. doi:https://doi.org/10.1177/1933719111419246.

95. Nadeau-Vallee M, Quiniou C, Palacios J, et al. Novel Noncompetitive IL-1 Receptor-Biased Ligand Prevents Infection- and Inflammation-Induced Preterm Birth. J Immunol. 2015. doi:https://doi.org/10.4049/jimmunol.1 500758.

96. Liong S, Di Quinzio MK, Fleming G, et al. Prediction of spontaneous preterm labour in at-risk pregnant women. Reproduction. 2013. doi:https://doi.org/1 0.1530/REP-13-0175.

97. Ruiz RJ, Jallo N, Murphey C, et al. Second trimester maternal plasma levels of cytokines IL-1Ra, II-6 and IL-10 and preterm birth. J Perinatol. 2012. doi: https://doi.org/10.1038/jp.2011.193.

98. Le TM, Nguyen LH, Phan NL, et al. Maternal serum uric acid concentration and pregnancy outcomes in women with pre-eclampsia/eclampsia. Int J Gynaecol Obstet. 2019. doi:https://doi.org/10.1002/ijgo.12697.

99. Fotiou M, Michaelidou AM, Athanasiadis AP, et al. Second trimester amniotic fluid glucose, uric acid, phosphate, potassium, and sodium concentrations in relation to maternal pre-pregnancy BMI and birth weight centiles. J Matern Fetal Neonatal Med. 2015. doi:https://doi.org/10.3109/14767058.2 014.937692

100. Menni C, Migaud M, Kastenmuller G, et al. Metabolomic Profiling of LongTerm Weight Change: Role of Oxidative Stress and Urate Levels in Weight Gain. Obesity (Silver Spring). 2017. doi:https://doi.org/10.1002/oby.21922. 
101. Harrison RF. Amniotic fluid uric acid levels in the maturing fetus. J Obstet Gynaecol Br Commonw. 1972. doi:https://doi.org/10.1111/j.1471-0528.1972. tb12904.X.

102. Koski KG, Fergusson MA. Amniotic fluid composition responds to changes in maternal dietary carbohydrate and is related to metabolic status in term fetal rats. J Nutr. 1992. doi:https://doi.org/10.1093/jn/122.2.385.

103. Li J, Guan L, Zhang H, et al. Endometrium metabolomic profiling reveals potential biomarkers for diagnosis of endometriosis at minimal-mild stages. Reprod Biol Endocrinol. 2018. doi:https://doi.org/10.1186/s12958-018-0360-z.

\section{Publisher's Note}

Springer Nature remains neutral with regard to jurisdictional claims in published maps and institutional affiliations.

Ready to submit your research? Choose BMC and benefit from:

- fast, convenient online submission

- thorough peer review by experienced researchers in your field

- rapid publication on acceptance

- support for research data, including large and complex data types

- gold Open Access which fosters wider collaboration and increased citations

- maximum visibility for your research: over $100 \mathrm{M}$ website views per year

At BMC, research is always in progress.

Learn more biomedcentral.com/submissions 